\title{
The Use of Team-Based Learning as a Diagnostic Tool in the Chemistry Teaching-Learning
}

\author{
Nairley Cardoso Sá Firmino \\ Antônio Mateus Paiva Salustiano \\ Brazil \\ Diego Farias Firmino \\ Brazil \\ Luciana Rodrigues Leite \\ Brazil \\ Brazil
}

Team-Based Learning (TBL) is a teaching strategy developed in phases - the pre-class, the guarantee of preparation, and the application of concepts - which proposes to break with traditionalism in the classroom. In this essay, TBL was used as a diagnostic tool for the learning of students. One hundred and twenty-seven students from the Dentistry course of a University Center in Ceará enrolled in the Chemistry module participated in this study. They were divided into three classes (two regular and a special one, composed of the repeaters students) and participated in two stages: preparation and guarantee of preparation. To systematize the activities, initially, the students were instructed to study at home, with the didactic material previously provided (pre-class). The second stage, consisting of individual, collective tests and feedback from the professor, had the data categorized and analyzed, in association with the narrative of the students. There was an improvement in the comprehension of the students after the collective work, the difficulties were higher in the content of intermolecular forces, and the special class expressed the need for directed pedagogical support. It was concluded that the use of TBL as a diagnostic mechanism is feasible, once it provides a complete visualization of the educational process and assists in directing the teaching work. Besides, this essay contributes to the professor training, once it increases the possibilities of using TBL at the university level and corroborates for the educators to recognize it as an adjunct of the pedagogical work, entirely. Finally, the innovative character of this study is reiterated, since similar publications were not, yet, identified in the literature of the area.

Keywords: Team-based learning; Chemistry teaching; Higher education; Diagnosis.

\section{Introduction}

Contemporary education is permeated by conflicting and uncertain situations. Regarding, specifically, to educational institutions, it is observed that, in general, there are difficulties in adapting to the speed in which changes are established in society and the predominance of the use of methodologies that maintain the centrality of the educational process in the figure of the professor. This reality contributes to perpetuating the recognition of students as subjects who 'receive' knowledge and not as those capable of building their knowledge. 
The context illustrated in the previous paragraph is part of the pedagogical routine of most Brazilian higher education courses. Consequently, Masseto (2004, p. 198) indicate, among countless aspects that demand modification in this reality, the need to "[...] substitute the role of the professor as the class teacher and transmitter of information, for the role of pedagogical mediator, developing a partnership and coresponsibility with their students, working as a team [...]". He also indicates that the French-Napoleonic model, which inhabits the origin of Brazilian Higher Education courses, remains firmly rooted in contemporary university education, so that, subsequent changes do not exempt the need for changes.

This paper was organized based on the understanding that emerges of the need to insert changes in the current circumstances. Consequently, the active methodologies are expressed as resources that contribute to modifying the relations professorstudent, student-student, and student-knowledge. One of the objectives of the active methodology is to enable the students to become protagonists of the educational process, in a pedagogical practice in which the professor acts as an advisor, mediator, and facilitator of learning, that is, their role is not restricted to the exposure of the contents and subsequent evaluation of the process, expanding to a more consistent work of conjunct and continuous formulation of knowledge.

In the recent literature, several methodologies that share this perspective, are identified, such as the "inverted classroom" whose fundamental idea resides in the student studying previously the material indicated by the professor, so that the presential meeting becomes the opportunity to clarify doubts, to develop activities and to deepen the knowledge (Bergmann \& Sams, 2016). There is also the Problem-Based Learning (PBL), which uses real-life difficulties to orientate discussions and studies, aiming to contribute to the motivation and concentration of the students in the learning of conceptual, procedural and attitudinal knowledge (Ribeiro, 2008) - among others.

In this essay, Team-Based Learning (TBL) was specifically used. It constitutes an active methodology formed by a set of sequenced teaching-learning practices (Krug et al., 2016) that requires the evocation of the previous experiences and knowledge of the students to be effectuated, and whose application occurs in phases: individual preparation (pre-class); guarantee of preparation and application of concepts (Bollela et al., 2014). The preparation phase consists of an individual study (pre-class) in which students are responsible for acquiring their knowledge, by materials directed by the professor. The next stage occurs in two parts, an individual test, and a group test, without consulting the teaching materials, followed by appeal and feedback from the educator. The third phase consists of solving-problem situations applied by the professor (Oliveira et al., 2018).

This learning strategy was utilized to support the learning of undergraduate Dentistry students from a Ceará University Center, regarding the contents of Chemistry. In this course, chemical knowledge is necessary to understand the processes of cavities and dental erosion, composition, and properties of dental materials, structure, and action 
of anesthetics, reactions involved in radiological revelations, among other specificities. Therefore, in the Chemistry module, elementary contents are studied, such as atomic structure, intermolecular forces, properties of the elements, among others.

The interest in the development of this paper came from the fact that, in the context of this course, reports from the students about the learning difficulties in the module, were frequent. It was deliberated, therefore, to develop a work that would assist in identifying the main difficulties of the students. The TBL was utilized in this process because, it is assumed that it would facilitate the accomplishment of this objective, in addition to, at the same time, energize the pedagogical work in the classroom, contributing to the autonomy of academics and the establishment of other types of learning modalities.

It is a common knowledge that the principle of TBL resides in the fact that it is a constructivist educational strategy that aims to stimulate, in the student, the development of advanced levels of learning (Michaelsen \& Sweet, 2008 cited in Nascimento \& Silva (2019). Nevertheless, the practical experience of using TBL, in the academic field, by the authors of this investigation, made them questioned and discuss the possibilities of using this educational strategy as a diagnostic tool for student learning. So, this report was structured based on this directing question: "What is the potential of TBL as a diagnostic tool for the learning of Chemistry by a group of Dentistry students?"

Therefore, this research was structured to diagnose the chemistry learning of a group of academics from Ceará, by using TBL, as well as presenting and analyzing the possibility of using TBL as a diagnostic mechanism for student learning. The analysis of these data was used to redirect teaching strategies, in addition to assisting in the identification of the content that needed to be further explored. It is reiterated, the notion of the innovative character, once TBL was used as a diagnostic tool, and considering that this perspective is rarely addressed in the literature of the area. However, it was based on the understanding that the results obtained in the phases from TBL provide better visualization of the comprehension of the students, once it allows individual and collective aspects to be analyzed, by means of objective and subjective information collected during the process.

\section{Active Methodologies and the Chemistry Teaching in Dentistry}

Over time, abstractions and lack of context, among other factors, contribute to students creating a negative image of scientific disciplines. Thus, researchers have highlighted for some time, the existence of a crisis in scientific education, once the teaching of these disciplines is structured around the memorization of formulas and knowledge that limits learning (Santos et al., 2013). The difficulties, involved in learning, contribute to becoming the contents uninteresting to the students. Besides, according to Melo and Santos (2012), the abstract nature of the concepts leads to difficulties in the comprehension of scientific models and promotes the emergence of alternative conceptions. 
With regard specifically to the teaching of Chemistry, it is observed that during secondary education, the majority of the students do not acquire specific knowledge necessary for personal development in other stages of their studies. Belo et al., (2019) confirm this perspective by indicating that the high failure rates in some courses in the Higher Education network, comes from the learning difficulties in Chemistry originated in high school. It is understood, therefore, that these difficulties need to be overcome, once the chemical knowledge is essentially necessary for a solid understanding of biological processes, mainly aimed at students in the health area.

For dentistry students, chemical knowledge is at the center of characteristics themes of the dental professional. Some relations between these two areas of knowledge were demonstrated by Storgatto et al. (2017) when exploring the chemical balance reactions that represent the enamel demineralization and mineralization and the concept of $\mathrm{pH}$, processes related to cavities and dental erosion. These same authors emphasize that in radiology, the revelations and fixations of the images occur through oxidation-reduction reactions. Besides, there are chemical processes involved in the use of substances that assist to decrease or to block painful sensations, including the evolution of these processes over time. This relation also exists in the characterization of restorative materials, which needs a comprehension of the concepts of chemical bonds and polymerization processes, in addition to knowledge about the properties of the chemical elements that compose these materials.

Considering the intimate relationship between Chemistry and Dentistry, we attempt to improve the teaching and learning processes to enhance the comprehension of the students of biological processes. One aspect that contributes to this reality is the use of strategies that encourage an active position of academics. Active methodologies turn the roles of authors involved in the educational process - professors and students - more evident by re-signifying the role of the educator as a facilitator of learning and the student as co-responsible for their development. According to Macedo et al. (2018, p. 2), "[...] active methodologies have a critical-reflexive education concept, based on stimuli in the teaching-learning process, resulting in involvement by the student in the search for the knowledge".

Studies report interesting pedagogical experiences, as described by Chacon, Carvalho and Ribeiro (2016) who proceeded an analysis on the articulation of the Chemistry with the Dentistry, using conceptual maps; and Storgatto et al., (2017) who addressed this relation by the use of contextualization. Therefore, considering that this study addresses the experience of using TBL in the teaching of Chemistry for future dentists, providing, in addition to the diversification of teaching methods, a perspective of its use as a learning diagnosis, some aspects of this methodology are highlighted as follows. 


\section{Learning Based in Teams}

TBL was created in 1970 by Larry Michaelsen, aiming at improving learning and developing collective work (Oliveira et al., 2018). In this sense, Sweet and Michaelsen (2012) mentioned in Nascimento and Silva (2019) considers TBL to be an instructional system that improves intellectual and social participation of the students. Gullo et al., (2015) complement this perspective, considering that the TBL stimulates the interest of the student in the search for information, rendering him responsible for his learning and co-responsible for the learning of his colleagues. Furthermore et al. (2018) affirm that TBL enhances the commitment in the learning process, emphasizing aspects directed to communication abilities and interpersonal relations, with an evolution regarding the exercise of doubt.

The application of TBL occurs in phases - "individual preparation" (pre-class); "guarantee of preparation" and "application of concepts" with the last two occurring in the classroom (Bollela et al., 2014). The "preparation" phase requires from the professor, the organization of the material to be provided, and from the student, the commitment to prepare individually. The "preparation guarantee" is divided into sub-phases, in which the student is initially subjected to individual multiple-choice tests, with no consultation of the teaching materials. The next sub-phase consists of collective tests, also without the possibility to research, however, with discussions between the members of the groups, authorizing the exchanges of experiences, knowledge, and questions that express pertinent doubts. Based on the dialogues, the members of each group must select the alternative that best represents the thoughts of the group, built with the argumentation. Then, the feedback of the group is provided, and the appeals process starts, in which the members utilize the consultation material in the arguments. This phase ends with the feedback of the professor (Krug et al., 2016; Oliveira et al., 2018; Nascimento and Silva, 2019). The phase of "application of concepts" occurs in a posterior moment, in which problem-situations involving the knowledge addressed in the "guarantee of preparation" stage are approached. According to Nascimento and Silva (2019), although the phases of the TBL might seem simple, conducting it requires abilities, so that, the discussions might become engaging and participatory.

The TBL is based on constructivism, solidified in the perspective that the professor should act as a learning facilitator in an environment devoid of authoritarianism and that privileges equality (Bollela et al., 2014). Therefore, TBL aims to promote the development of high-performance learning teams and provide them opportunities to engage in meaningful learning activities (Krug et al., 2016). The advantage of using TBL is the possibility of working with large classes, in groups of five to seven members randomly formed, avoiding affective connections. There is no need for numerous professors or multiple prepared rooms (Bollela et al., 2014).

Although it has its origins in business courses, TBL is used with a higher frequency in courses in the health area. Studies report the use of this strategy in medical education (Krug et al., 2016; Oliveira et al., 2018). In addition, Oliveira et al. (2016) published 
an article in which they present the TBL for utilization in the teaching of Physics, in higher education courses, and highlight the need for changes in the teaching methods, based on traditionalism, aiming decreasing evasion rates. In chemistry teaching, an experience was expressed by Walters (2013), in which the author affirms that $95 \%$ of students described the reading assignments as focused and useful, and $81 \%$ said they enjoyed the TBL format. Besides, the author reports that TBL required less effort than other activities to be developed, the teams became cohesive and competitive, the peer pressure ensured that students arrived at classes with some level of preparation, and there was a solid comprehension of the subject.

As previously described, the recurrence of TBL provides numerous benefits for learning. The potential for its use as a diagnostic tool, however, has not yet been investigated. Therefore, the purpose of this study is to use the TBL, also, as an auxiliary mechanism for the professor in the identification of contents in which students have learning disabilities. It is a common knowledge that this type of action, assists by improving the leading of the teaching strategies, and the TBL, with support in individual and collective results, allows the visualization of a panorama of student knowledge about the content - this being studied. This fact collaborates with the pedagogical action of the professor, while the identification of this reality facilitates the structuring of interventions deeply focused on the needs of students. Regarding these interventional processes, Pinheiro and Rebouças (2018) emphasize that they do not occur by the simple application of diagnostic assessments, therefore, it is necessary to consider their functionality and importance, because, through the data collected by the diagnostic instruments, activities, and actions to be performed, are elaborated. Also, regarding the diagnostic activities, Luckesi (2005) emphasizes that it is necessary to understand and to perform them, through a commitment to a pedagogical concept.

\section{Methodology}

This research is characterized as qualitative-quantitative in terms of its approach, and exploratory, in terms of its objectives, since it is based in Minayo (2014) comprehension that the qualitative and quantitative data complement each other when interacting dynamically, contributing to the enrichment of the analyses, while the exploratory character is related to the fact that this type of study provides familiarity with the studied field, and is applicable in initial studies to obtain an overview about certain facts (Gil, 2002 ).

The subjects of this investigation were 127 Dentistry undergraduates, specifically the students of the Chemistry module, distributed in three classes: two regular classes from the first semester and another formed only by students who had already failed the discipline (special class). The classes were identified by A (49 students), B (47 students) and $\mathrm{C}$ ( 31 students), with class- $\mathrm{A}$ being composed of the academics who were repeating the module.

The use of TBL as a diagnostic tool in these classes occurred in two phases: 
preparation and guarantee of preparation. In the preparation stage, previous studies of materials regarding the contents of the atomic structure, periodic table and chemical bonds were performed, under the guidance of the professor. In the next phase, the guarantee of diagnosis occurred by applying a diagnostic tool, according to the steps described in Figure 1, oriented by Bollela et al. (2014).

\begin{tabular}{|l|}
\hline Preparation \\
\hline Previous study about: \\
- $\quad$ Atomic structure \\
- $\quad$ Periodic table \\
\hline
\end{tabular}

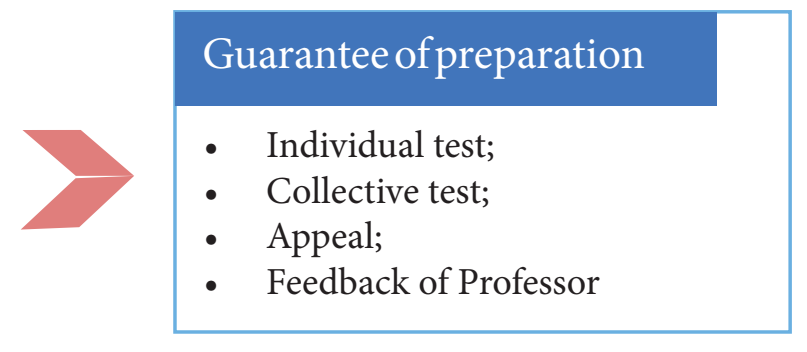

Figure 1. Representation of the phases of TBL developed in this study

The data collection occurred, effectively, during the phase of guarantee of preparation, which, was instrumentalized according to the following:

1. The students answered the diagnostic instruments (Annex 1), individually, without consulting educational materials (individual test).

2. Teams of five or six people were formed and submitted again to the questions, however, with the possibility of discussing without consulting the didactic materials, and achieved a consensus in the answer (collective test).

3. Mediated by the professor, the groups presented their responses and with the use of didactic material, appeals occurred between the groups along with the feedback of the educator (appeal and feedback).

The analysis of data from individual and collective tests facilitates to diagnose the learning level of each class. Therefore, the diagnostic mechanism was organized with multiple-choice questions (items), in which there was one correct answer, and the distractors represented the incorrect options. When applying the tests, the following guidelines were provided to students: they could select only one option and receive four points if they answered correctly or zero points if they marked a distractor. There was also the alternative of checking two options. If one of these options was the correct one, the group received two points, and if it were a distractor they would receive zero.

The categorization of the results was performed considering the content approached in each question, and the knowledge necessary for the student to discard the incorrect options or to mark the correct one. Therefore, according to the alternative selected, the following categories were established: Comprehension (C), Doubts (D) and Non-Comprehension (NC), where $\mathrm{C}$ was related to the students selecting the correct answer; D when two options were elected, one being the correct; $\mathrm{NC}$, when one or two distractors were marked (See Figure 2). 


\begin{tabular}{|c|l|c|c|}
\hline Alternatives & Conditions & Ponctuation & Categorization \\
\hline 1 & Template & 4 & $\mathrm{C}$ \\
\hline 1 & Distractor & 0 & $\mathrm{NC}$ \\
\hline 2 & Template and Distractor & 2 & $\mathrm{D}$ \\
\hline 2 & Distractor and Distractor & 0 & $\mathrm{NC}$ \\
\hline
\end{tabular}

Figure 2. Punctuation and categorization of the answers in TBL

In the tabulation of the results, the points were counted, and the groups were ranked according to the score obtained. The responses of the items, acquired through the individual and collective phases, were tabulated, and the graphs were elaborated using the Microsoft Excel Office program. In addition, the discussions and reflections developed between the groups in the phases of appeal and feedback were described in a logbook for further analysis of the narratives. According to Nunes et al. (2017), the evaluation of the statements has the proposal of being a "script" for researchers from different areas who need to interpret data through the speeches and/or dialogues.

It is essential to add that the students were informed about the objectives and procedures of the study, and were willing to participate with no objection. They signed a Free and Informed Consent Form agreeing with the referred participation. Furthermore, following the ethical precepts of research, the privacy of the participants was valued, therefore, protecting their identities.

\section{Results and Discussion}

To the presentation of the results, initially, the items of the TBL referring to the applied tests, correlating the contents of the statements of the questions (Annex 1) to the options, are analyzed. In the sequence, data related to the learning diagnosis of the students are exposed, considering individual and collective aspects, in addition to presenting and comparing the results of each class. And, finally, the narratives of the participants are analyzed regarding the content of chemistry addressed.

The items in the diagnostic questionnaire were analyzed considering the correlation between the main content contemplated in the statements of these items and the contents of the options, as presented in Figure 3. This analysis facilitated the creation of categorization criteria related to the resolvability of the item and the possible questions in the learning process.

It is noticeable that the items privileged in a correlated manner three notable axes of the contents of Chemistry: atomic structure, the periodic table, and chemical bonds. According to Pazinato (2016), these contents are fundamental topics in Chemistry, once they cover the intimate nature of matter and its transformations. 


\begin{tabular}{|c|l|l|}
\hline Items & Main content & Correlation of the contents in the options \\
\hline 01 & Atomic Structure & $\begin{array}{l}\text { Periodic Properties } \\
\text { Intermolecular Forces }\end{array}$ \\
\hline 02 & Atomic Structure & $\begin{array}{l}\text { Periodic Properties and Table } \\
\text { Chemical Bonds } \\
\text { Polarity }\end{array}$ \\
\hline 03 & Intermolecular Forces & $\begin{array}{l}\text { Molecular and Atomic Structure } \\
\text { Chemical Bonds } \\
\text { Polarity }\end{array}$ \\
\hline 04 & Periodic Properties & $\begin{array}{l}\text { Atomic Structure } \\
\text { Periodic Table }\end{array}$ \\
\hline 05 & Atomic Structure & Chemical Bonds \\
\hline
\end{tabular}

Figure 3. Main contents and correlations presented in the statements and in the options of the items in TBL

The results of the categorization, presented in Figure 4, were performed with support in the criteria of selecting the options of the items in the TBL. These data correspond to the totality of students, participants of the study, and also express the relation between the individual and collective aspects of the work that was developed in class.

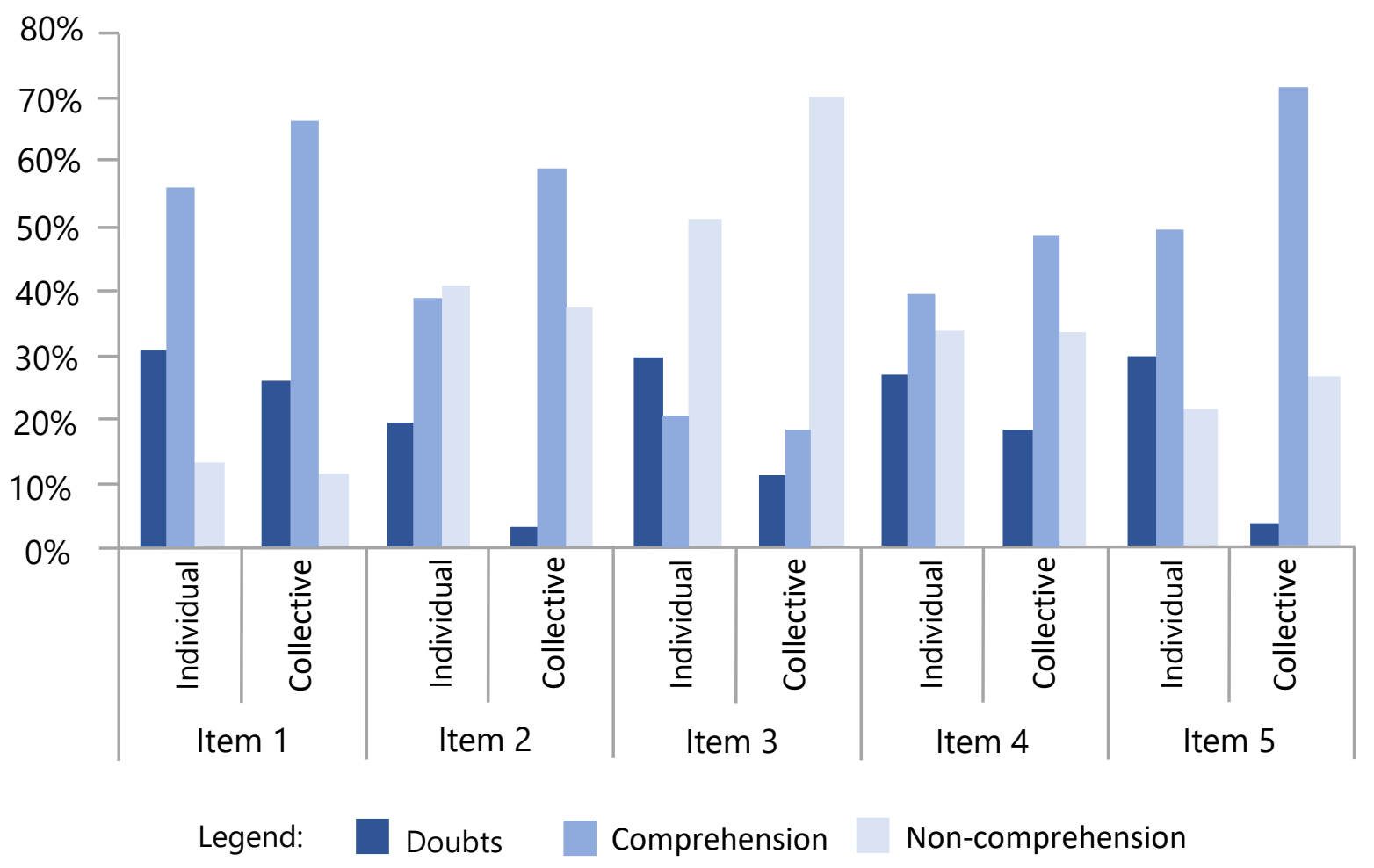

Figure 4. Results, in percentage, of the categorization of the answers to the TBL items 
According to Figure 4, considering the individual data of the first item, more than $50 \%$ of the students marked the answer template, thus, being in the category Comprehension (C), 31\% were placed in the category Doubt (D) and approximately $10 \%$ in the category Non-Comprehension (NC) category. By correlating with the data of the groups in this previous item, it was possible to notice that the collective discussion privileged the comprehension (C).

In the second item, individually, non-comprehension (NC) represented $41 \%$, and in the collective work, it was reduced to $37 \%$. The highlight in this item, however, it is observed in the relation between doubts (D) and comprehension (C), since, comparing the individual and collective data, there was a decrease, by five times, in doubts (D) and a $20 \%$ increase in comprehension (C) in the direction from individual to collective, therefore, in this item, the collective work privileged the elucidation of doubts. These two items addressed the content of the atomic structure.

In the third item, it was observed that in the collective data, non-comprehension (NC) increased to 70\%, while doubts (D) decreased when compared to individual data. Considering that the variation of comprehension (C) was only $1 \%$, it was noticed that the collective work, in this case, contributed to the increase of non-comprehension (NC) and that this content needs to be revised, since the majority of the students did not completely assimilate it, or had questions about it. The main content of item three is intermolecular forces, which is related to the concept of polarity, the structure of substances, and their behavior in solutions. This content is directly related to the properties of materials, such as temperature, melting and boiling points, solubility, density, and viscosity, in addition, to permeate numerous fields of knowledge, such as the health area, in which students need to comprehend intermolecular forces in biological contexts, which are related, for example, to the classification of substances into hydrophobic and hydrophilic, in the solvation process, gas exchange in the alveoli, interactions of DNA strands, among others.

At least two factors that intervene in the difficulties of the students in assimilating this content were identified. The first of them concerns the learning inconsistencies deriving from basic education, considering that an extensive number of studies have revealed that the development of medium-level content does not suit the expectations described by the official documents, that govern the Brazilian education (Miranda et al., 2018). Therefore, chemical concepts of basic education need to be reinforced in higher education.

The second factor concerns the alternative conceptions that students acquire over time, thus, as highlighted by Miranda et al. (2017), the abstraction of intermolecular forces content leads to the use of explanatory models, which might convert the subject into complex and generate alternative conceptions to scientific models. During this investigation, it was possible to identify not only these conceptions but also the fact that some of these conceptual errors are transmitted between the students. This contributes to the students pass the teaching levels with some difficulties in comprehending the 
content and highlights the relevance of the role of the professor in accompanying the group discussions, to minimize the dissemination of these misconceptions about chemical knowledge and to enable the promotion of a conceptual evolution of these subjects.

In the fourth item, it was observed that the collective work favored comprehension (C). The data presented that doubts (D) decreased, and non-comprehension (NC) remained practically constant. The highest value of $C$, however, has not yet represented $50 \%$ of students in this item. The results related to the fifth item indicate a similar pattern to all other items in category doubts (D) questions decreased in the collective. However, it was noticed that the percentage of C increased by $20 \%$, and $\mathrm{NC}$ also increased to a lesser proportion. It is, therefore, confirmed the understanding that the collective work needs to be accompanied by the educator, to propagate the learning, and to dissipate the misconceptions. The fifth item approaches concepts such as atomic number, electrical neutrality, mass and volume ratio of the nucleus, and electrosphere and valence layer. Thus, it was identified that approximately $25 \%$ of students need to improve on this subject.

According to Medeiros (2013), the study of the periodic table for teaching the periodic properties of the elements has been performed, in the same form, by educators, since the beginning of the 20th century. The periodic classification of the elements permits the study of physical and chemical properties, but the success in their learning is achieved when the content is approached in association with atom concepts and with the atomic theories, which are also, as well as the periodicity of the elements, abstract and distant from the reality of the students. According to Souza and Cardoso (2008), the act of teaching and learning Chemistry or, in particular, chemical periodicity, requires processes of theorization, elaboration, and re-elaboration of models that permit the interpretation and explanation of the results by the students.

In addition to the analysis of the items, considering the totality of students, the results per class were verified, and are presented in Table 1.

Based on the indicators in this table, the situation of each class was analyzed. In class $\mathrm{A}$, it was noticed that, in the individual results of the second item, $68 \%$ of $\mathrm{NC}$ were students in that class. This behavior was also observed, in the third, fourth, and fifth items. In class B, in items one, two, four, and five, it was observed that the results of comprehension (C) were superior to those of non-comprehension (NC) in the individual data. It is important to mention the results for the second item collectively, in which all groups marked the template. Class $\mathrm{C}$ exhibited a behavior similar to class $\mathrm{B}$.

Classes B and C are regular, thus, formed by students admitted to the course. Class A consists of students who reproved in the module in previous semesters. According to the data presented in Table 1, it was possible to identify the difficulties of students in class A persisted from the previous semester to the next. Therefore, it was concluded that support or leveling strategies are necessary for classes of this type. The provision of special-class is characterized as an action to support students with comprehension 
difficulties. Based on the data of this study, it was identified the need to complement the pedagogical support, to be provided with the use of leveling, monitoring, didactic materials, and a more directed accompanying of the professor. In regular classes, it was observed that there are difficulties in assimilating the contents, however, the collective work provided an increase in comprehension (C).

Table 1. Categorization of individual and collective responses, to the TBL items, according to the class

\begin{tabular}{|c|c|c|c|c|c|c|c|c|c|}
\hline \multirow{2}{*}{ Items } & \multirow{2}{*}{ Categories } & \multicolumn{4}{|c|}{ Individual } & \multicolumn{4}{|c|}{ Collective } \\
\hline & & Total & TA & TB & TC & Total & TA & TB & TC \\
\hline \multirow{3}{*}{01} & $\mathrm{D}$ & 39 & 21 & 11 & 7 & 7 & 2 & 1 & 4 \\
\hline & $\mathrm{C}$ & 71 & 24 & 27 & 20 & 17 & 7 & 7 & 3 \\
\hline & $\mathrm{NC}$ & 17 & 4 & 9 & 4 & 3 & 1 & 1 & 1 \\
\hline \multirow{3}{*}{02} & $\mathrm{D}$ & 25 & 8 & 10 & 7 & 1 & 1 & 0 & 0 \\
\hline & $\mathrm{C}$ & 49 & 5 & 29 & 15 & 16 & 1 & 9 & 6 \\
\hline & NC & 53 & 36 & 8 & 9 & 10 & 8 & 0 & 2 \\
\hline \multirow{3}{*}{03} & $\mathrm{D}$ & 37 & 11 & 16 & 10 & 3 & 1 & 1 & 1 \\
\hline & $\mathrm{C}$ & 26 & 9 & 10 & 7 & 5 & 1 & 3 & 1 \\
\hline & $\mathrm{NC}$ & 64 & 29 & 21 & 14 & 19 & 8 & 5 & 6 \\
\hline \multirow{3}{*}{04} & $\mathrm{D}$ & 34 & 16 & 9 & 9 & 5 & 4 & 1 & 0 \\
\hline & $\mathrm{C}$ & 50 & 15 & 23 & 12 & 13 & 4 & 6 & 3 \\
\hline & $\mathrm{NC}$ & 43 & 18 & 15 & 10 & 9 & 2 & 2 & 5 \\
\hline \multirow{3}{*}{05} & $\mathrm{D}$ & 38 & 18 & 13 & 7 & 1 & 1 & 0 & 0 \\
\hline & $\mathrm{C}$ & 62 & 13 & 27 & 22 & 19 & 3 & 8 & 8 \\
\hline & $\mathrm{D}$ & 39 & 21 & 11 & 7 & 7 & 2 & 1 & 4 \\
\hline
\end{tabular}

Subtitle. TA - Class A, TB - Class B, TC - Class C, C - Comprehension, D - Doubts, NC - Noncomprehension.

It is important to discuss the monitoring of the collective work, because, in the results obtained after the formation of the groups, a decrease in comprehension (C) and an increase in non-comprehension $\mathrm{NC}$ were noticed, mainly in class A regarding items two, three and five. Some strategies to the conduction of the collective work might be used; it is suggested, opportunely, for the professor to be responsible for the formation of the groups, to mix the students based on their characteristics. According to Johnson et al. (1999) mentioned in Teodoro et al. (2015), the educator should distribute the students in groups, considering the homogeneous formation when trying to promote the domain of specific competencies, and heterogeneous to discuss the assignment requested by the professor. Finally, there is an improvement in the comprehension and quality of reasoning. In a study by Fatareli et al. (2010), the professor, after organizing the groups, distributed different functions to the members, providing the opportunity for all the members to contribute in a balanced form in realizing the activities. 
Based on the assumption, another strategy to be adopted is to provide moments of discussion between students and professor, in order to clarify the questions and thus avoid the spread of conceptual errors. In order to provide interaction and discussion, the educator as a learning facilitator is a fundamental axis of this process, so he must use strategies, during the application of the TBL, that enable this interlocution. According to Oliveira et al. (2018), it is the responsibility of the professor to instigate the participation of all members of the group and access them equally, accompanying the core of the discussions. In addition, these authors suggest that, in the development of TBL activities, questions containing two correct options should be elaborated, with one more correct than the other, as this encourages the student to search the literature and develop arguments for the appeal stage.

After the individual and collective tests, appeals between groups occurred along with feedback from the professor. At this stage, the groups socialized the responses, and in cases of disagreement, discussions were realized, with the right to consult the didactic materials. During the discussions, it was possible to identify the reasoning that led to conceptual errors, which were explored by the educator in the intervention process. Here are some of the narratives:

Class A: "We make mistakes because we forget that the atomic number is the same number of protons" (Group 1); "We scored B and D because we had questions about what the dipole-dipole interaction really is" (Group 2).

Class B: "In those squares are the up and down arrows, I just don't know why that is so" (Group 3); "I don't know what an atom is in the fundamental state" (Group 4).

Class C: "The ionization energy of bromine is not greater than that of chlorine because bromine comes after chlorine in the column" (Group 5). "Hydrogen bonds are the strongest, we got confused" (Group 6).

Supported by the discussions, it was observed that the concepts of the number of protons and the relationships with other subatomic particles were not acceptably comprehended. Supported by the discussions, it was observed that the concepts of the number of protons and the relationships with other subatomic particles were not acceptably comprehended. Groups 1 and 3 expressed this fact in their reports, and it was also possible to notice in the utilization of the mass numbers to perform the electronic distribution. Finally, it was concluded that part of the students, regardless of being able to express themselves correctly when approaching the subject of atom structure with the nucleus and electrosphere, have questions when applying in daily situations where it is necessary to master these concepts. In this context, Camargo et al. (2018) emphasize that the use of models and abstractions is among the main difficulties related to the teaching of atomic models. This difficulty, according to them, is due to the fact that the study of the atom involves the submicroscopic level, that is, it is something that is not possible to be touched or visualized.

It is important to consider that Chemistry has its particular language, using 
symbols, graphics, and images that represent concepts, and the knowledge of that language is essential for a better comprehension of the processes and their application in chemical reactions in biological means, as is the case of dentistry students. However, considering the speech of Group 3, it was noticed that the use of the box model in the representation of the orbitals, for some students, promoted mechanical learning, meaning that, the student knew how to do, but did not comprehend the meaning. In this sense, the importance of scientific literacy is emphasized, since, according to Sasse-Ron (2008) mentioned in Miranda et al. (2015), when scientifically literate, students develop intellectually and cognitively, facilitating decision-making and critical thinking. In this process abilities are developed, such as: classifying information, improving logical reasoning, raising and testing hypotheses and others.

Based on the statement of Group 5, it was assumed that the periodic properties and its form of disposition in the periodic table, were summarized to the direction of the arrows. In other words, students restricted themselves to the orientation of the arrows to respond to activities, a method generally used in elementary education. Thus, it was not possible to conclude if there was real learning about the meaning of ionization energy or if the response was the result of remembering the orientation of the arrow in relation to the increase of the ionization energy over the periodic table. The authors Berbaum and Maldaner (2016) emphasize the use of the techniques popularly known as "decorate", which provide temporary memorization of some meaningless concepts which lead to learning in which the student is unable to provide meaning to the knowledge and elaborate a chemical thought.

In the statements of Groups 2 and 6, it was noticed that questions about intermolecular interactions persisted. Considering the data in Graphic 1, the referred content was not assimilated by $70 \%$ of the students, and $11 \%$ of them remained in doubt, even after the collective work. To learn intermolecular forces, the student needs to comprehend that when there is an approximation between atoms, molecules, or ions, two distinct phenomena occur, a reaction or an interaction (Miranda et al., 2018). In a chemical reaction, a conversion between one or more substances in different ones occurs as a consequence of the formation or rupture of chemical bonds. An interaction is related to the attraction or repulsion between molecules or ions among themselves, without breaking or forming new chemical bonds. The energy involved in this process is, in general, smaller than that involved in a chemical reaction.

In this case, it was noticed a need to understand several concepts involved in the learning of intermolecular forces, such as chemical reaction, chemical bonds, attraction and repulsion, and energy exchanges. It is important to consider that when the student does not master these concepts, there is a reflection on the application of knowledge in different contexts and that this difficulty in comprehending the chemical contents by students, in general, is owing to the fact that Chemistry it is studied in a fragmented form, involving abstract concepts and highly specific symbolic language (Camargo et al., 2018). 


\section{Conclusion and Implications}

The results of this study exhibited the feasibility of the utilization of TBL as a diagnostic tool, by enabling the identification of content in which students presented major difficulties and assisting them to comprehend the relations in individual and collective learning. Therefore, it was possible to notice that, in general, the dominant difficulties of the students resided in the content of intermolecular forces. It was hypothesized that the cause of these difficulties rests on the high level of abstraction of the referred content, on the learning inconsistencies originally from secondary education, and on alternative conceptions that students acquire during their school career, considering that erroneous conceptions about the content, were identified through the collected narratives. This fact highlights the importance of establishing a dialogical environment in the classroom and the need for collective work to be carefully conducted to facilitate learning and add elements inherent to the formulation of knowledge.

These data enhance the importance of the professor as a mediator in the teaching and learning processes, thus the systematic monitoring of the educator, since the formation of groups to the feedback after the appeal phase, tends to permit the clarification of questions. Additionally, it is reiterated the idea that the use of quantitative and qualitative results provided a complete visualization of the classes. Also, after this process of learning characterization, it was observed that the special class needs distinctive teaching strategies and mechanisms that support, pedagogically, the students in overcoming the difficulties encountered in the study of Chemistry. It is important to highlight that the detection of these deficiencies tends to assist the professor in the elaboration of interventions because, with this information, the work will be directed to answer questions, and to facilitate learning.

Therefore, it is essential to emphasize the innovative character of this study, since the publications involved in this theme, among which are included Walters (2013), Oliveira et al. (2016) and Oliveira et al. (2018), approach aspects related to the dynamization of teaching strategies, describe the stages for using the method, present a quantitative data which reflect the acceptance of students about the methodology and demonstrate perspectives of application in other areas. The innovation of this study is related to the fact that in the scope of this investigation it was presented and discussed a manner of using TBL as a diagnostic tool for student learning. It is not known that this perspective has been, yet, identified in the literature of the area. Therefore, contributing to expanding the conjunction of utilities of this methodological approach, in the classroom.

It is known that other studies have been developed aiming to present new forms of using TBL in the classroom. Some of them are aligned with the proposal expressed in this article, such as Cunha et al. (2019), who experienced TBL, as an evaluation strategy, being a substitute for traditional evaluation, in a discipline of the Medicine course. These studies add contributions to the context of professor training, considering that they enable the contact of educators with options for inserting new methodological 
resources in their pedagogical practice and assist in the comprehension of the range of possibilities intrinsic to the use of TBL in the school context, whether as a strategy to promote motivation, engagement, facilitate learning, assess student knowledge, or even diagnose content that needs to be better comprehended by students.

Regarding the professor training, it is decisive to consider that the studies indicate the need for a change in education, in the sense of reinventing teaching and learning methods (Araújo, 2011 cited by Rech, 2016). In this perspective, the educator must teach students to think autonomously to the point of being agents that transform their reality (Freire, 2015). Therefore, the implementation of active methodologies, such as TBL, requires specific continuous training, so that the professor might properly conduct this process and even expand it according to the needs of the students.

Therefore, it is expected that the dissemination of this experience, will assist professors to comprehend and use TBL, not only as a methodological resource for diversifying their classes but also to recognize and to use it, as an adjunct to pedagogical work entirely, considering that the results of this study indicate that the use of TBL provides a complete visualization of the educational process and assist in the direction of teaching work, which corroborates to the viability of this approach as a diagnostic tool.

It is relevant to highlight the possibilities of expanding this essay, considering that only two stages of TBL - preparation and preparation guarantee, was approached. Further study will be able to envision the application of all stages, including the application of concepts, as a moment of intervention to be developed by the professor, based on the identification of the individual and collective needs of the academics, coming from the previous stages. In addition to enabling the contextualization of scientific concepts, this perspective verifies a possible conceptual change by students and contributes to the expansion of the set of didactic-methodological possibilities of inserting TBL in the school context. Besides, other strategies for measuring the data collected and organizing the teams may be inserted, at the discretion of the creativity and objectives of the professor.

\section{Acknowledgment}

To the UNINTA University Center, Sobral, Ceará and to the students, who participated in the study. 


\section{References}

Belo, T. N., Leite, L. B. P., \& Meotti, P. R. M. (2019). As dificuldades de aprendizagem de química: Um estudo feito com alunos da Universidade Federal do Amazonas [Learning difficulties in Chemistry: A study with students from the Federal University of Amazonas]. Scientia Naturalis, 1(3), 1-9.

Berbaum, L. C. M., \& Maldaner, O. A. (2016). Estratégias de ensino do conteúdo Tabela Periódica e sua relação com a aprendizagem conceitual em aulas de Química [Teaching strategies of the content Periodic Table and its relationship with conceptual learning in Chemistry classes]. In XVII Jornada de Extensão - Ciências Exatas e da Terra. UNIJUÍ.

Bergmann, J., \& Sams, A. (2016). Sala de aula invertida: Uma metodologia ativa de aprendizagem [Inverted classroom: An active learning methodology]. LTC.

Bollela V. R., Senger M. H., Tourinho, F. S. V., \& Amaral E. (2014). Aprendizagem baseada em equipes: Da teoria à prática [Team-based learning: From theory to practice]. Revista Medicina (Ribeirão Preto), 47(3), 293-300. http://dx.doi.org/10.11606/issn.2176-7262. v47i3p293-300

Camargo, L. C., Asquel, S. de S., \& Oliveira, B. R. M. (2018). Problematizando o ensino de modelos atômicos: Estudo das representações e o uso de um jogo didático [Questioning the teaching of atomic models: study of representations and the use of a didactic game]. Revista ACTIO: Docências em Ciências, 3(3), 197-213.

Chacon, E. P., Carvalho, L. J., \& Ribeiro, C. M. R. (2016). A Odontologia como tema para o ensino de Química: Estudo e possibilidades por meio de mapas conceituais. Ensino, Saúde e Ambiente, 9(2), 45-62. http://dx.doi.org/10.22409/resa2016.v9i2.a21223

Chacon, E. P., Carvalho, L. J., \& Ribeiro, C. M. R. (2016). A Odontologia como tema para o ensino de Química: estudo e possibilidades por meio de mapas conceituais. [Dentistry as a theme for teaching Chemistry: Study and possibilities through concept maps]. Ensino, Saúde e Ambiente, 9(2), 45-62. http://dx.doi.org/10.22409/resa2016.v9i2.a21223

Cunha, C. R. O. B. J. da, Ramsdorf, F. B. M., \& Bragato, S. G. R. (2019). Utilização da Aprendizagem Baseada em Equipes como Método de Avaliação no Curso de Medicina [The use of Team-Based Learning as an Evaluation Method in the Medical Course]. Revista Brasileira de Educação Médica, 43(2), 208-215. https://doi.org/10.1590/1981$52712015 \mathrm{v} 43 \mathrm{n} 2 \mathrm{rb} 20180063$

Fatareli, E. F., Ferreira, L. N. de A., Ferreira, J. Q., \& Queiroz, S. L. (2010) Método cooperativo de aprendizagem Jigsaw no ensino de cinética química [Cooperative Jigsaw learning method in the teaching of chemical kinetics]. Química Nova na Escola, 32(3), $161-168$.

Gil, A. C. (2002). Como Elaborar Projetos de Pesquisa [How to elaborate research projects]. 4. ed. Atlas. 
Gullo, C., Ha, T. C., \& Cook, S. (2015). Twelve tips for facilitating team-based learning. Medical Teacher, 37(9), 819-824. http://dx.doi.org/10.3109/0142159X.2014.1001729

Krug, R. R., Vieira, M. S. M., Maciel, M. V. de A., Erdmann, T. R., Vieira, F. C. de F., Koch, M. C., \& Grosseman, S. (2016). O "Bê-Á-Bá” da Aprendizagem Baseada em Equipe [The "Bê-Á-Bá" of Team-Based Learning]. Revista Brasileira de Educação Médica, 40(4), 602610. http://dx.doi.org/10.1590/1981-52712015v40n4e00452015

Luckesi, C. C. (2005). Avaliação da Aprendizagem Escolar: Estudos e proposições [Evaluation of School Learning: Studies and propositions]. Cortez.

Macedo, K. D. S., Acosta, B. S., Silva, E. B., Souza, N. S., Beck, C. L. C., \& Silva, K. K. D. (2018). Metodologias ativas de aprendizagem: Caminhos possíveis para inovação no ensino em saúde [Active learning methodologies: possible paths for innovation in health education]. Anna Nery Revista de Enfermagem, 22(3), 1-9. http://dx.doi. org/10.1590/2177-9465-EAN-2017-0435

Masseto, M. (2004). Inovação na Educação Superior [Innovation in the High Education]. Interface - Comunicação, Saúde, Educação, 8(14), 197-202. http://dx.doi.org/10.1590/ S1414-32832004000100018

Medeiros, M. A. (2013). Avaliação do conhecimento sobre periodicidade química em uma turma de Química Geral do ensino a distância [Assessment of knowledge about chemical periodicity in a distance learning General Chemistry class]. Química Nova, 36(3), 474-479. http://dx.doi.org/10.1590/S0100-40422013000300019

Melo, M. R., \& Santos, A. O. (2012). Dificuldades dos licenciandos em química da UFS em entender e estabelecer modelos científicos para equilíbrio químico [Difficulties of undergraduate chemistry students at UFS in understanding and establishing scientific models for chemical equilibrium]. In Anais do XVI Encontro Nacional de Ensino de Química. UFBA.

Minayo, M. C. S. (2014). Pesquisa social: Teoria, método e criatividade [Social research: Theory, method and creativity]. 33. ed. Vozes.

Miranda, A. C. G., Braibante, M. E. F., \& Pazinato, M. S. (2017). Concepções alternativas sobre forças intermoleculares: Um estudo a partir das publicações da área de ensino [Alternative conceptions of intermolecular forces: A study based on publications in the teaching field]. In Anais do X Congreso Internacional sobre Investigación en Didáctica de las Ciencias.

Miranda, A. C. G., Braibante, M. E. F., \& Pazinato, M. S. (2018). Tendências do ensino e aprendizagem de forças intermoleculares a partir da análise de publicações em periódicos nacionais e internacionais [Trends in teaching and learning of intermolecular forces from the analysis of publications in national and international journals]. Revista Electrónica de Enseñanza de las Ciencias, 17(2), 394-419. 
Miranda, M. de S., Suar, R. de C., \& Marcondes, M. E. R. (2015). Promovendo a alfabetização científica por meio de ensino investigativo no ensino médio de Química: Contribuições para a formação inicial docente [Promoting scientific literacy through investigative teaching in high school chemistry: Contributions to initial professors' education]. Revista Ensaio, 17(3), 555-583. http://dx.doi.org/10.1590/198321172015170302

Nascimento, F. G. do, \& Silva, G. R. (2019). Utilização do método Team-Based Learning (TBL) no processo de aprendizagem e desenvolvimento de habilidades na disciplina de custos [The use of the Team-Based Learning (TBL) method in the process of learning and developing skills in the cost discipline]. In Anais do XVI Congresso USP de Iniciação Científica em Contabilidade. USP.

Nunes, L. S., Paula, L. de, Bertolassi, T., \& Faria Neto, A. (2017) A análise de narrativas como instrumento para pesquisas qualitativas [The analysis of narratives as an instrument for qualitative research]. Revista Ciências Exatas, 23(1), 9-17.

Oliveira, B. L., Lima, S. F., Rodrigues, L. S., \& Pereira Junior, G. A. (2018). Team-Based Learning como forma de Aprendizagem Colaborativa e Sala de Aula Invertida com centralidade nos estudantes no processo ensino aprendizagem [Team-Based Learning as a form of Collaborative Learning and Inverted Classroom with centrality in students in the teaching-learning process]. Revista Brasileira de Educação Médica, 42(4), 86-95. http://dx.doi.org/10.1590/1981-52712015v42n4rb20180050

Oliveira, T. E., Araújo, I. S. \& Veit, E. A. (2016). Aprendizagem Baseada em Equipes (Team-Based Learning): Um método ativo para o Ensino de Física. [Team-Based Learning: Anactive method for teaching physics]. Caderno Brasileiro de Ensino de Física, 33(3), 962-986. http://dx.doi.org/10.5007/2175-7941.2016v33n3p962

Pazinato, M. S. (2016). Ligações Químicas: Investigação da construção do conhecimento no ensino médio [Chemical connections: An investigation of the construction of knowledge in high school]. (Tese Doutorado). Universidade Federal de Santa Maria, Santa Maria.

Pinheiro, D. P., \& Rebouças, J. A. da S. M. (2018). A importância da avaliação diagnóstica no projeto de nivelamento matemático com discentes do ensino médio integrado [The importance of diagnostic evaluation in the mathematical leveling project with integrated high school students]. In V Congresso Nacional de Educação - CONEDU. CECON.

Ribeiro, L. R. de C. (2008). Aprendizagem Baseada em Problemas - PBL: Uma experiência no Ensino Superior [Problem-Based Learning - PBL: An experience in Higher Education]. Edufscar. http://dx.doi.org/10.7476/9788576002970

Santos, A. O., Silva, R. P., Andrade, D., \& Lima, J. P. M. (2013). Dificuldades e motivações de aprendizagem em Química de alunos do ensino médio investigadas em ações do (PIBID/UFS/Química) [Difficulties and motivations for learning in Chemistry of high school students investigated in actions of (PIBID / UFS / Química)]. Scientia Plena, 9(7), $1-6$. 
Silva, S. C., Colle, F. E. S., Cavichioli, D., \& Souza, R. F. (2018). Aprendizado e desenvolvimento de habilidades no curso de Contabilidade: Uma pesquisa-ação com o método Team-Based Learning (TBL) [Learning and skills development in the Accounting course: Action research with the Team-Based Learning (TBL) method]. Revista Enfoque: Reflexão Contábil, 37(3), 1-19. http://dx.doi.org/10.4025/enfoque.v37i3.39579

Souza, K. A. F. D., \& Cardoso, A. A. (2008). Aspectos macro e microscópicos do conceito de equilíbrio químico e de sua abordagem em sala de aula [Macro and microscopic aspects of the concept of chemical equilibrium and its approach in the classroom]. Química Nova na Escola, 27, 51-56.

Storgatto, G. A., Braibante, M. E. F., \& Braibante, H. T. S. (2017). A Química na Odontologia [Chemistry in Dentistry]. Química Nova na Escola. 39(1), 4-11. http:// dx.doi.org/10.21577/0104-8899.20160054

Teodoro, D. L., Cabral, P. F. de O., \& Queiroz, S. L. (2015). Atividade cooperativa no formato Jigsaw: Um estudo no ensino superior de Química [Cooperative activity in a Jigsaw format: A study in higher education in Chemistry]. ALEXANDRIA Revista de Educação em Ciência e Tecnologia, 8(1), 21-51. http://dx.doi.org/10.5007/1982$5153.2015 \mathrm{v} 8 \mathrm{n} 1 \mathrm{p} 21$

Walters, D. E. (2013). Team-Based Learning applied to a Medicinal Chemistry Course. Medical Principles and Practice, 22(1), 2-3. http://dx.doi.org/10.1159/000342819

\section{ANNEX 1 - Diagnostic Instruments}

Team-based learning

Content: Atomic Structure, Periodic Table and Chemical Bonds

01. (UFC) When atoms are ionized, their properties are, drastically, altered. As examples, we can relate an aggregate of bromine $\left(\mathrm{Br}_{2}\right)$ molecules, which possess a red color. Bromide ions $\left(\mathrm{Br}^{-}\right)$, present in sodium bromide crystals, $\mathrm{NaBr}$, are colorless; metallic sodium $(\mathrm{Na})$ reacts violently with water $\left(\mathrm{H}_{2} \mathrm{O}\right)$, while $\mathrm{Na}^{+}$ions are stable in an aqueous medium $\left[\mathrm{Na}^{+}\left(\mathrm{H}_{2} \mathrm{O}\right)_{n}\right]$; chlorine molecules $\left(\mathrm{Cl}_{2}\right)$ constitute a poisonous gas with a light green color. The chloride ions $\left(\mathrm{Cl}^{-}\right)$, present in salt $(\mathrm{NaCl})$, are colorless and low in toxicity. Check the correct alternative.

A) The ionic rays of anions are smaller than those of the respective neutral atoms that originate them.

B) The properties of atoms and their source ions are strongly dependent on valence electrons.

C) The ionization energies of the ions are identical to those of the respective source atoms.

D) Hydrated sodium ions $\left[\mathrm{Na}^{+}\left(\mathrm{H}_{2} \mathrm{O}\right)_{\mathrm{n}}\right]$ are a typical example of dipole-dipole interactions.

E) The ionization energy of bromine is greater than that of chlorine, since its atomic radius is greater. 
02. (UFC with modifications) Human teeth are composed essentially of calcium carbonate, $\mathrm{CaCO}_{3}$, and hydroxyapatite, $\left[\mathrm{Ca}_{10}\left(\mathrm{PO}_{4}\right)_{6}(\mathrm{OH})_{2}\right]$. Despite being the human body with the hardest composition, teeth are attacked by acids, originating cavities. When used regularly, toothpaste containing fluoride ions ( $\left.\mathrm{F}^{-}\right)$induce the replacement of hydroxyl ions in hydroxyapatite, forming fluorapatite $\left[\mathrm{Ca}_{10}\left(\mathrm{PO}_{4}\right)_{6}(\mathrm{OH})_{2}\right]$. This substance presents higher hardness and is less susceptible to acid attack, turning the teeth more resistant to cavities. (Data: $\mathrm{F}^{9}$ ). Regarding fluoride, check the correct alternative:

A) It is located in the first period of the periodic table.

B) Forms bivalent anion, since its electronic distribution ends at $\mathrm{p}^{6}$.

C) From the electronic distribution of fluorine, it is possible to see that the secondary quantum number is 1 , and the magnetic number is 0 .

D) Among halogens, fluorine has the lowest electronegativity and is, therefore, the most reactive.

E) Fluoride ions participate in the fluorapatite molecule, through non-polar covalent bonds with calcium atoms.

03. (UFC with modifications) The water is presented in a liquid state, at room temperature, and atmospheric pressure, and boils at a temperature that is about $200 \mathrm{C}$ higher than that of the theoretically predicted boiling point, at the absence of hydrogen bonds. Concerning hydrogen bonds, check the correct alternative.

A) It occurs between molecules, where the hydrogen atom is covalently bonded to the atoms with higher electropositivity, by their pairs of bonding electrons.

B) It originates from the attraction between the hydrogen atoms of a water molecule, which has a partial positive charge, and the oxygen atom of another molecule, which has a negative partial charge.

C) Among intermolecular interactions, hydrogen bonds are the weakest. This factor promotes surface tension, turning water capable of forming globs, or allowing an insect to land on its surface.

D) The greater the electronegativity of the hydrogen-bonded to the atom in the molecule, the higher the negative charge on the hydrogen, and the weaker the interaction with the positive extremity of the other molecule.

E) They are considered weaker interactions when compared with the London forces and play a fundamental role in the chemistry of living beings.

04. (UFPE with modifications) Consider the following process:

$$
\begin{aligned}
& \text { (a) } X(g) \longrightarrow X^{+}(g)+\text { e- }(g) \\
& \text { (b) } X^{+}(g) \longrightarrow X^{+2}(g)+e-(g) \\
& \text { (c) } Y(g)+\text { e- (g) } \longrightarrow \text { Y- (g) }
\end{aligned}
$$

It is possible to affirm that:

I. The ionization energy of equation "b" is higher than that of the equation "a". 
II. If $\mathrm{Y}$ is the atom of a halogen, we can affirm that process (c) releases energy.

III. The energy required to accomplish the process (b) is less than that required for the process (a).

IV. Processes (a) and (b) express, respectively, the first and second ionization energies of atom $\mathrm{X}$.

It is correct what is stated in:
A) I.
B) I e II.
C) II e III.
D) I, II e IV.
E) I, II, III e IV.

05. (UEMG with modifications) Scientific and technological development facilitates the identification of atoms of natural chemical elements and also permits to synthesize atoms of chemical elements not found on the surface of the earth. On the concepts related to atomistic, check the correct alternative.

A) The number of protons in an atom characterizes it, thus, each atom has an atomic number, which differentiates it from the others.

B) The atom in the fundamental state, to maintain electrical neutrality, must have the same amount of protons and neutrons.

C) An atom can acquire an electric charge, converting in a cation or anion. Therefore, it is necessary to lose or gain protons in the valence layer.

D) The valence layer of an atom does not influence the processes involving chemical bonds: electron transfer and sharing.

E) The atom consists of a nucleus and electrosphere. The electrosphere occupies a large volume and, therefore, has a large mass. The core has a small volume and a positive charge. 


\title{
Nairley Cardoso Sá Firmino
}

${ }^{\circledR}$ https://orcid.org/0000-0002-7684-5371

Centro Universitário INTA - UNINTA

Coordenadoria de Formação Docente e Educação a Distância (CODED)

Sobral, Ceará, Brazil

nairleysafirmino@gmail.com

\author{
Antônio Mateus Paiva Salustiano \\ (1) https://orcid.org/0000-0001-6260-6751 \\ Centro Universitário INTA - UNINTA \\ Sobral, Ceará, Brazil \\ mateusgba09@hotmail.com \\ Diego Farias Firmino \\ ${ }^{0}$ https://orcid.org/0000-0003-3921-2089
}

Coordenadoria de Formação Docente e Educação a Distância (CODED)

Sobral, Ceará, Brazil

diego.firmino12@gmail.com

\section{Luciana Rodrigues Leite}

${ }^{\circledR}$ https://orcid.org/0000-0003-1915-6462

Universidade Estadual Vale do Acaraú

Centro de Ciências Exatas e Tecnológicas

Sobral, Ceará, Brazil

luciana_leite@uvanet.br

Submitted on 04th May 2020

Accepted on 04th September 2020

Published on 15th December 2020 